\title{
Prevalence of metabolic syndrome in adolescents living in Mthatha, South Africa
}

\author{
This article was published in the following Dove Press journal: \\ Therapeutics and Clinical Risk Management \\ 7 February 2017 \\ Number of times this article has been viewed
}

\author{
Morongwe Annah \\ Sekokotla' \\ Nandu Goswami \\ Constance Rufaro \\ Sewani-Rusike' \\ Jehu Erapu Iputo 3 \\ Benedicta Ngwenchi \\ Nkeh-Chungag ${ }^{4}$ \\ 'Department of Human Biology, \\ Faculty of Health Sciences, Walter \\ Sisulu University, Mthatha, South \\ Africa; ${ }^{2}$ Gravitational Physiology and \\ Medicine Research Unit, Institute of \\ Physiology, Medical University of Graz, \\ Graz, Austria; ${ }^{3}$ Department of Medical \\ Education, Faculty of Health Sciences, \\ Walter Sisulu University, ${ }^{4}$ Department \\ of Biological and Environmental \\ Sciences, Faculty of Natural Sciences, \\ Walter Sisulu University, Mthatha, \\ South Africa
}

Objective: Metabolic syndrome (MetS), defined as the clustering of three of five risk factors (hypertension, obesity, triglyceridemia, dyslipidemia and hyperglycemia), is being increasingly mentioned among children and adolescents despite there being no consensus on how it should be defined in this set of population. Furthermore, very few studies have focused on MetS in children and adolescents in sub-Saharan populations. This study, therefore, aimed at determining the prevalence of the MetS and contributing risk in adolescents living in Mthatha, South Africa.

Research design and methods: Four hundred and ten adolescents (age range: 13-18 years, both sexes) were recruited into this cross-sectional study. In addition to a lifestyle questionnaire being administered, anthropometric measurements (weight, height and waist circumferences) were carried out for each participant. Fasting venous blood was collected for lipid profile and blood glucose assessments. Blood pressure was also measured. MetS was assessed using appropriate diagnostic criteria for children and adolescents.

Results: Complete data sets were collected from 371 participants. Females showed an elevation in the risk factors for MetS. Of the 371 participants, $40.2 \%$ were overweight/obese (47.5\% females; $22.5 \%$ males). MetS was diagnosed in 3.1\% female participants compared with $6.0 \%$ in male participants. Conclusions: More risk factors for the MetS are seen among the overweight/obese as compared to lean adolescents. Given the fact that childhood overweight/obesity often continues into adulthood, it is important to address the causes of increased risk for MetS earlier in life to prevent the development of disease in adult life.

Keywords: metabolic syndrome, adolescent health, overweight, obesity

\section{Introduction}

In adults, metabolic syndrome (MetS) often refers to a cluster of symptoms that may increase the risk of developing cardiovascular diseases (CVDs) and type 2 diabetes mellitus. ${ }^{1}$ MetS includes obesity, high blood pressure, hyperglycemia or insulin resistance, ${ }^{2}$ low levels of high-density lipoprotein cholesterol (HDL-C) and elevated triglyceride levels. ${ }^{3}$ Assessment of MetS in patients is useful for clinicians to determine disease progression, especially as MetS is associated with insulin resistance, ${ }^{2}$ oxidative stress $^{4}$ and chronic low-grade inflammation. ${ }^{2}$ Evaluation of MetS, however, remains a challenge. For instance, even though MetS is more common in obese persons, lean people have also been shown to have three or more of the five risk factors for MetS, thus leading them to be classified as having MetS. ${ }^{1,5}$ Therefore, a modified definition of MetS is required. Currently, the National Cholesterol Education Program (NCEP ATP III, 2000) criteria for defining MetS are used. ${ }^{6}$

MetS in children and adolescents is not well defined, and there is no current consensus on its definition as cutoff points for considered risk factors are not standardized. ${ }^{7}$ The International Diabetes Federation - which has specific criteria for children 10 to $<16$ years old 
while older children are defined by adult criteria ${ }^{8}$ - defines MetS in children as obesity plus two or more of four other criteria including systolic blood pressure (SBP) $\geq 130 \mathrm{mmHg}$ or diastolic blood pressure (DBP) $\geq 85 \mathrm{mmHg}$ (which are higher than the BP values normally considered as prehypertension in adolescents), ${ }^{9}$ regardless of age and sex. The World Health Organization (WHO) criteria consider the coexistence of any three or more risk factors for MetS with or without obesity. ${ }^{10}$ Besides not being specific for children and adolescents, the WHO criteria require the use of SBP $>95$ th percentile, meaning that the child must be hypertensive and have a body mass index $(\mathrm{BMI})>95$ th percentile. However, the National Cholesterol Education Program (NCEP ATP III, 2000) has specific criteria - which were further modified by Cook et $\mathrm{al}^{11}-$ for defining MetS in 12- to 19-year-old adolescents. The NCEP criteria for defining MetS in adolescents are the presence of any three or more risk factors, but they require that both SBP and DBP are $\geq 90$ th percentile for age and sex, whereas the definition of prehypertension requires that SBP and/or DBP $\geq 90$ th percentile for age and sex. The Guidelines for prevention of atherosclerosis in childhood and adolescence (IDPAIA, 2006) criteria for defining MetS includes a BMI > 85th percentile for age and sex and requires a measurement of plasma insulin levels. ${ }^{12}$ Furthermore, recent studies have recommended the use of a continuous metabolic syndrome (cMetS) risk score for describing the existence and contribution of MetS to clinical measurements. $^{13}$

Studies from developing countries show that obesity is becoming a public health concern, especially among children and adolescents who present with symptoms of MetS. ${ }^{14-16}$ Over- and undernutrition coexist among children and adolescents in South Africa, a country that recently emerged from political oppression. However, to what extent cardiometabolic syndrome is associated with adolescents in underprivileged areas of South Africa is not known. We, therefore, carried out this study in Mthatha, a small town in South Africa. We hypothesized that in adolescents, with a prevalence of $>20 \%$ hypertension and prehypertension, ${ }^{17}$ there is a corresponding occurrence of signs and symptoms of MetS. As this could lead to the development of cardiovascular risk in later life in these adolescents, our study is particularly important. We are not aware of any study that has examined aspects related to cardiometabolic syndrome in black adolescents from underprivileged areas in South Africa.

\section{Materials and methods Study design}

A cross-sectional cohort study was conducted at selected high schools in Mthatha, Eastern Cape Province, South Africa.

\section{Background and selection criteria for this study}

As pointed out in the previous section, each of the criteria for defining MetS has its limitations. The NCEP criteria adjusted for adolescents are the best ones that could be used for our study. In our study, in addition, we adopted the definition of Cook et al - which is adopted from the NCEP - defined as the coexistence of any three of the following risk factors: fasting glucose $\geq 110 \mathrm{mg} / \mathrm{dL}$, waist circumference (WC) $>90$ th percentile, serum triglyceride $\geq 110 \mathrm{mg} / \mathrm{dL}$, $\mathrm{HDL}<40 \mathrm{mg} / \mathrm{dL}$ and SBP and/or DBP $\geq 90$ th percentile for age, sex and height. ${ }^{11}$ We also used the cMetS to determine the prevalence of MetS in this adolescent cohort.

\section{Inclusion and exclusion criteria}

Thirteen- to 18-year-old high school students (both male and female) were recruited for the study. Participants were excluded from the study if they were pregnant, breastfeeding, ill, handicapped in such a way that obtaining anthropometric measurements was difficult, on blood pressure-lowering medication, endurance athletes, or having any self-reported comorbidity or cardiovascular or endocrinological disorders.

\section{Sample size calculations}

Sample size was calculated as 246 based on the previous studies. ${ }^{17}$ To account for dropouts and missing values, a total of 410 school-attending adolescents were recruited.

\section{Ethical approval}

The approval to conduct this study was obtained from the Walter Sisulu University Ethics Committee (Ref No: 014/009) in accordance with the ethical standards laid down by the Declaration of Helsinki (2000). The purpose of the study was explained to the participants and each of them was provided the participant information sheet and consent forms to take home to get their parents' and/or guardians' consent. Only students whose parents returned signed consent forms were recruited into the study. Each participant gave signed informed assent indicating voluntary participation in the study. In accordance with the National Data Protection Acts, each participant was assigned a code, and data/samples were stored anonymously.

\section{Data collection and anthropometric measurements}

A structured questionnaire was used to obtain histories of dietary habits, health status as well as demographic data. Height was measured to the nearest $0.1 \mathrm{~cm}$ without shoes, 
using a stadiometer with the shoulders in relaxed position. A validated Omron Body Composition Monitor (BF511) designed to measure body composition in persons aged 8-80 years old - was used to measure BMI. The equipment was calibrated to each participant's age, height and sex. WC was measured to the nearest $0.1 \mathrm{~cm}$ at the smallest point between the iliac crest and the lower rib margin at the end of normal expiration, using a nonelastic tape with participants standing with both feet together.

\section{Blood pressure measurements}

Study participants were advised not to exercise 48 hours preceding the measurements. They were asked to avoid caffeine or any stimulants for 24 hours prior to the measurements. All measurements were carried out on school premises between 9.00 am and $11.00 \mathrm{am}$ in a quiet room with adequate lighting. Upon arrival in the designated rooms, the participants were asked to rest in the seated position for 5 minutes, after which blood pressure was measured using an automated blood pressure machine Microlife BP A100 Plus model. This instrument is equipped with a single- and repeated-measure function, which measures blood pressure three times and displays a calculated average value. Appropriate cuff sizes were used based on the size of the participant's arm. The cuff was wrapped around the upper arm and maintained in place with Velcro on the cuff. Blood pressure and heart rates were determined automatically. The data obtained were converted to percentiles for age and sex.

\section{Biochemical parameters}

Fasting venous blood was collected from all the participants for measurement of blood glucose, total cholesterol, triglycerides, HDL-C and low-density lipoprotein cholesterol (LDL-C). Serum was collected into microeppendorf tubes and stored at $-80^{\circ} \mathrm{C}$ until it was processed. The fully automated Cobas ${ }^{\circledR}$ C501/502 (Roche) system was used for determining serum lipid profiles.

\section{Reference values used in this study}

Overweight and obesity were defined as BMI $>85$ th percentile but $<95$ th percentile while obesity was defined as BMI $>95$ th percentile. The cutoff value for fasting venous glucose was $\geq 100.8 \mathrm{mg} / \mathrm{dL}$ according to the recommendations of American Diabetes Association (ADA, 2000). ${ }^{18}$ The cMetS score was determined using the online calculator provided by the University of West Virginia, USA (http://publichealth.hsc.wvu.edu/biostatistics/metabolic-syndrome-severity-calculator/\#2) for 12-19-year-old children. The cMetS score calculation takes into account the adolescent's height, weight, sex, serum triglyceride, HDL-C, fasting glucose, SBP, DBP and ethnicity. Generated results include BMI $z$ scores, Met $z$ scores and cMetS percentiles. These calculations have been validated by Gurka et al. ${ }^{3}$

\section{Statistical analysis}

Stata MP/14 version was used for data analyses. The skewness/kurtosis test was used to verify normality of all analyzed data before analysis. Descriptive statistics were performed to determine differences between lean and overweight/obese participants. Linear regression was used to construct models for multiple regression to estimate contribution of each variable to the development of MetS. Foods listed in the questionnaire were pooled in broad categories, such as dairy for milk, cheese, ice cream, hot chocolate and yoghurt. Percentile for number of times participants consumed groups of foods or exercised was determined statistically and the 75 th percentile and greater were denoted as 1 while lower percentiles were denoted as 0 .

\section{Results}

A total of 410 (283 females and 127 males) participants were enrolled in the study. Complete data were only available from 371 (255 females and 116 males) participants and are reported here. There was no age difference between females and males. The female participants had a significantly higher BMI and WC compared with males. Blood glucose was similar in both males and females (Table 1). Compared with males, females had significantly higher values for total cholesterol, LDL-C and HDL-C. Serum triglyceride levels were similar in both groups.

Table I Demographic data and biochemical parameters of participants by sex and body size

\begin{tabular}{lll}
\hline & Females & Males \\
\hline $\mathrm{N}$ & 255 & $1 \mathrm{I} 6$ \\
Age (years) & $15.2 \pm 0.1$ & $15.3 \pm 0.1$ \\
Body mass index $\left(\mathrm{kg} / \mathrm{m}^{2}\right)$ & $25.4 \pm 0.3^{* *}$ & $22.3 \pm 0.4$ \\
Waist circumference $(\mathrm{cm})$ & $78.1 \pm 0.7^{* *}$ & $74.0 \pm 1.0$ \\
Serum glucose $(\mathrm{mg} / \mathrm{dL})$ & $70.2 \pm 1.9$ & $68.7 \pm 3.3$ \\
Total cholesterol $(\mathrm{mg} / \mathrm{dL})$ & $160.8 \pm 2.1^{* *}$ & $140.5 \pm 3.9$ \\
Triglyceride $(\mathrm{mg} / \mathrm{dL})$ & $67.8 \pm 2.1$ & $68.0 \pm 2.9$ \\
Low-density lipoprotein & $89.9 \pm 1.6^{* *}$ & $78.7 \pm 1.8$ \\
cholesterol $(\mathrm{mg} / \mathrm{dL})$ & & \\
High-density lipoprotein & $60.3 \pm 0.8^{* *}$ & $51.9 \pm 1.0$ \\
cholesterol (mg/dL) & & \\
\hline
\end{tabular}

Notes: Data are expressed as mean \pm standard error of mean. Comparison between female or male; $* * P<0.01$. 
Table 2 Individual risk factors for metabolic syndrome and prevalence of metabolic syndrome as defined by the presence of three of five known risk factors

\begin{tabular}{|c|c|c|}
\hline Risk factors for MetS & Females, $\mathrm{n}(\%)$ & Males, $\mathrm{n}(\%)$ \\
\hline Body mass index $\geq 85$ th percentile & $|2|(47.5)$ & $28(24.1)$ \\
\hline$W C \geq 80 \mathrm{~cm}$ (females) & $102(40)$ & $9(6.0)$ \\
\hline \multicolumn{3}{|l|}{ WC $\geq 94 \mathrm{~cm}$ (males) } \\
\hline $\mathrm{HT} /$ pre-HT & $83(32.6)$ & $38(32.8)$ \\
\hline High-density & $63(24.7)$ & $44(37.9)$ \\
\hline \multicolumn{3}{|l|}{ lipoprotein $\leq 40$ th percentile } \\
\hline Trig $\geq 90$ th percentile & $21(8.2)$ & II (9.5) \\
\hline Serum glucose $\geq 100.8 \mathrm{mg} / \mathrm{dL}$ & $9(3.5)$ & $8(6.9)$ \\
\hline \multicolumn{3}{|l|}{ Number of risk factors for MetS } \\
\hline $\begin{array}{l}\text { Metabolic syndrome } \\
\text { ( } \geq 3 \text { risk factors) }\end{array}$ & $8(3.1)$ & $7(6.0)$ \\
\hline Two risk factors & $51(22.7)$ & $23(19.8)$ \\
\hline One risk factor & $101(39.6)$ & $35(30.2)$ \\
\hline No risk factor & $95(37.3)$ & $51(44.0)$ \\
\hline
\end{tabular}

Abbreviations: $\mathrm{HT}$, hypertension; MetS, metabolic syndrome; WC, waist circumference; Trig, triglyceride.

Of the 255 females, 121 (47.5\%) were either overweight or obese, whereas $28(24.1 \%)$ males were either overweight or obese. The prevalence of obesity in the cohort was $40.2 \%$ (Table 2). Besides the overweight/obesity criterion, both lean and overweight/obese male and female participants presented with various risk factors for MetS. Using Cook et al's definition for MetS, MetS was diagnosed in $6.0 \%$ of the male population compared to the female $(3.1 \%)$ population. ${ }^{11}$ Just over $39 \%$ of the study population did not have a risk factor for MetS while about $59.3 \%$ of the study population showed the presence of one or two risk factors. Obesity/overweight was the most prevalent risk factor (Table 2).

BMI $z$ scores were significantly higher in females $(1.2 \pm 0.05)$ as compared to males $(0.7 \pm 0.01)$. BMI $z$ scores were significantly higher in obese compared to lean participants (females: $1.9 \pm 0.04$ vs $0.62 \pm 0.05, P<0.01$; males: $1.8 \pm 0.13$ vs $0.32 \pm 0.07, P<0.01$; Table 3 ). cMetS $z$ scores were negative for female and male cohorts (Table 3 ). When participants were separated by sex, cMetS $z$ scores were still negative for lean female and male participants but showed strongly positive values in overweight/obese females compared to males $(0.37 \pm 0.05$ vs $0.05 \pm 0.19$, respectively). The MetS percentile also showed higher values in obese compared to lean participants (females: $62.8 \pm 1.6$ vs $37.5 \pm 3.3$, $P<0.01$; males: $52.4 \pm 6.2$ vs $34.6 \pm 2.4, P<0.01$; Table 3 ). Using the MetS definition of cMetS score $\geq$ the 90 th percentile, MetS was less prevalent in female (5.6\%) than in male $(6.7 \%)$ cohorts (Table 3$)$. While no lean female had a cMetS $\geq 90$ th percentile, $2.2 \%$ lean males had cMetS scores $>90$ th percentile. Compared with the NCEP III guidelines, by which MetS was diagnosed in 3.1\% females and $6.0 \%$ males, the continuous MetS risk score was more sensitive and was able to diagnose more participants with MetS (5.6\% females and $6.7 \%$ males).

After establishing the significant associations between independent variables and percentile cMetS scores, we created models and tested for the overall contribution of each factor to cMetS percentiles (Table 4). The adjusted $R^{2}$ was 0.87 with a $P$-value of 0.001 indicating a good fit of the model. The model shows that for every unit increase in BMI, there is a 2.6-fold increased risk for the MetS, while every unit increase in age reduced the risk for MetS 2.29 times. The other factors that increased MetS risk were mean systolic blood pressure (MSBP), fasting glucose, total cholesterol, triglycerides and non-HDL-C (Table 4). The MetS in this adolescent population seems to be strongly related to BMI, MSBP, serum glucose, total cholesterol and nonHDL-C and age.

Linear logistic regression was performed using the presence of MetS - defined as cMetS $>90 \%$ - as dependent variables and scores calculated from the lifestyle questionnaire as independent variables (Table 5). Responses to each question were computed and the $75 \%$ percentiles were used as cutoff points for low and high values to which the numerals 0 and 1 were assigned, respectively. Exercise was significantly $(P=0.041)$ associated with protection from MetS (Table 5).

Table 3 Metabolic severity risk score or continuous metabolic syndrome risk score

\begin{tabular}{|c|c|c|c|c|c|c|}
\hline & \multicolumn{3}{|l|}{ Females } & \multicolumn{3}{|l|}{ Males } \\
\hline & Cohort & Lean & $0 / 0$ & Cohort & Lean & $0 / 0$ \\
\hline Body mass index $z$ score & $1.2 \pm 0.05^{* *}$ & $0.62 \pm 0.05$ & $1.9 \pm 0.04^{\# \#}$ & $0.7 \pm 0.01$ & $0.32 \pm 0.07$ & $1.8 \pm 0.13^{\#}$ \\
\hline cMetS z score & $-0.06 \pm 0.04$ & $-0.44 \pm 0.04$ & $0.37 \pm 0.05 \#$ & $-0.02 \pm 0.06$ & $-0.47 \pm 0.9$ & $0.05 \pm 0.19^{\#}$ \\
\hline MetS percentile & $51.8 \pm 1.4$ & $37.5 \pm 3.3$ & $62.8 \pm 1.6 \#$ & $48.9 \pm 2.3$ & $34.6 \pm 2.4$ & $52.4 \pm 6.2^{\#}$ \\
\hline MetS $\geq 90$ th percentile & $12(5.6 \%)$ & 0 & $12(5.6 \%)$ & $6(6.7 \%)$ & $2(2.2 \%)$ & $4(4.5 \%)$ \\
\hline
\end{tabular}

Notes: MetS is defined as cMet score $\geq 90$ th percentile. ${ }^{*} * P<0.01$; $*^{*}$ indicates $P$-value for comparisons between sex cohorts; $\# P<0.01$; $\#$ indicates comparisons between females and males in the same sex group. Data presented as mean \pm standard error or $n(\%)$.

Abbreviations: cMet z score, continuous metabolic risk z score; MetS, metabolic syndrome; O/O, overweight/obesity. 
Table 4 Adjusted regression coefficients of continuous metabolic syndrome risk score expressed as percentile of various independent variables

\begin{tabular}{llll}
\hline & $\begin{array}{l}\text { Coefficient } \\
\text { of model }\end{array}$ & $\begin{array}{l}\text { 95\% confidence } \\
\text { interval }\end{array}$ & P-value \\
\hline Age & -2.29 & -2.97 to $-\mathrm{I} .6 \mathrm{I}$ & $0.00 \mathrm{I}$ \\
Body mass index $\left(\mathrm{kg} / \mathrm{m}^{2}\right)$ & 2.60 & $2.4 \mathrm{I}$ to 2.79 & $0.00 \mathrm{I}$ \\
$\begin{array}{l}\text { Mean systolic blood } \\
\text { pressure }(\mathrm{mmHg})\end{array}$ & 0.42 & 0.33 to 0.50 & $0.00 \mathrm{I}$ \\
$\begin{array}{l}\text { Glucose }(\mathrm{mg} / \mathrm{dL}) \\
\text { Total cholesterol }(\mathrm{mg} / \mathrm{dL})\end{array}$ & 0.37 & 0.35 to 0.40 & $0.00 \mathrm{I}$ \\
Triglyceride $(\mathrm{mg} / \mathrm{dL})$ & $0.1 \mathrm{I}$ & -0.78 to -63 & $0.00 \mathrm{I}$ \\
Non-high-density & 0.70 & 0.08 to 0.15 & $0.00 \mathrm{I}$ \\
lipoprotein cholesterol & & 0.62 to 0.78 & $0.00 \mathrm{I}$ \\
Constant $(y$-intercept) & -13.52 & $-3 \mathrm{I} .49$ to 4.45 & 0.14 \\
\hline
\end{tabular}

Note: The dependent variable here is percentile of the metabolic syndrome continuous scores.

Greater consumption of dairy products and animal proteins seemed to show a tendency toward an increased risk for MetS, although these odds ratios were not significant.

\section{Discussion}

In this study, we investigated the risk for the MetS in 13-18year-old African adolescents in Mthatha, South Africa. The study shows that MetS exists among both lean and obese adolescents but with a higher prevalence in males. In addition, more than half of our study population had two or more risk factors for MetS. Our results also show that physical exercise protects from the risk of MetS.

The concern about MetS arose from studies that showed a high prevalence of prehypertension/hypertension and overweight/obesity in children and adolescents in both rural and urban communities in South Africa. ${ }^{19,20}$ High blood pressure and obesity are two of the five criteria used traditionally to describe MetS. In our study, over $47.5 \%$ of females and $24.1 \%$ of males were overweight/obese. There is

Table 5 Linear logistic regression analysis of the association between selected independent variables and the presence of metabolic syndrome as defined by cMetS score $\geq 90 \%$

\begin{tabular}{llll}
\hline $\begin{array}{l}\text { Number of } \\
\text { times/week }\end{array}$ & $\begin{array}{l}\text { Odds } \\
\text { ratio }\end{array}$ & $\begin{array}{l}\text { 95\% confidence } \\
\text { interval }\end{array}$ & P-value \\
\hline Green vegetables & $0.831365 \mathrm{I}$ & $0.45 \mathrm{I}-\mathrm{I} .53$ & 0.553 \\
Dairy & $\mathrm{I} .704895$ & $0.930-3.13$ & 0.085 \\
Fatty foods & 0.8891876 & $45 \mathrm{I}-\mathrm{I} .75$ & 0.734 \\
Sweets & 1.063637 & $0.546-2.07$ & 0.856 \\
Animal protein & $\mathrm{I} .170858$ & $0.615-2.23$ & $0.63 \mathrm{I}$ \\
Nuts & 0.856 & $0.44 \mathrm{I}-\mathrm{I} .66$ & 0.646 \\
Carbohydrates & 0.9758898 & $0.463-2.06$ & 0.949 \\
Physical exercise & 0.4682099 & $0.226-0.98$ & $0.04 \mathrm{I}$ \\
\hline
\end{tabular}

Note: Presence of metabolic syndrome defined as cMetS score $\geq 90 \%$. Abbreviation: cMetS, continuous metabolic syndrome. a reported positive relationship between the degree of adiposity and the blood pressure in adolescents. ${ }^{21,22}$ Indeed, studies show that over $30 \%$ of obese adolescent boys and $23 \%-30 \%$ obese girls are hypertensive. ${ }^{23}$ Thus, increased prevalence of overweight/obesity in South African adolescents is an indication of increased risk for MetS, which is strongly associated with hypertension (another risk factor for MetS).

Obesity has been associated with abnormal lipid profiles in both adults and adolescents. ${ }^{24}$ This study also showed that males had lower HDL-C and total cholesterol. Several prospective studies have demonstrated that unfavorable lipid levels often continue into adulthood. ${ }^{25}$ Epidemiological studies have consistently shown a protective effect of HDL-C against CVDs, while low levels are associated with increased risk for MetS and may correlate directly with triglycerides. ${ }^{26}$ In our study, risk factors for MetS were more prevalent in obese males than females. While $6.0 \%$ males had MetS, only 3.1\% females fulfilled the three risk factor criteria as stipulated by Cook et al. ${ }^{11}$ Importantly, given that both overweight/obese and lean adolescents had three or more criteria for MetS, indicating that MetS does not occur only in overweight/obese persons, it was important to apply the cMetS risk scores to our study cohort. The cMetS scores provide information on MetS as a continuum and not a set of categorical cutoff points. ${ }^{27} \mathrm{cMetS}$ risk scores are, therefore, more relevant in pediatric research. In our study, cMetS risk score calculations showed a lower prevalence of MetS in female $(5.6 \%)$ than in male $(6.7 \%)$ cohorts. There were fewer males in this study, which might have influenced our results toward a higher prevalence for MetS. The overall prevalence of MetS in our study cohort, however, was $5.9 \%$, which is relatively low compared to a Brazilian study that reported a prevalence of up to $14 \%$ in a study involving 348 children who were $8-9$ years old. ${ }^{14}$ On the other hand, Ahrens et al, ${ }^{28}$ in a very large cohort study across eight European countries, reported a smaller but an important prevalence of MetS in 2-9-year-old children. The sample size in our study like the Brazilian study was relatively, very small compared to the European study, which may explain the relatively higher prevalence observed in our studies.

Our results showed that although overweight/obesity was more prevalent in females than males using either Cook et al's criteria or the cMetS risk scores, the MetS was more prevalent in males than in females. This may raise important concerns about the criteria for defining obesity in participants of southern African ancestry to whom WHO cutoff points may not be applicable. The WHO cutoff points for defining overweight and obesity were designed for Caucasians with 
a specific body structure and fat distribution pattern that is different from the body structure of South Africans. ${ }^{29}$

High intake of dairy, animal protein and sweets increased the risk of developing MetS, whereas fruits, vegetables, nuts and regular exercise were protective against MetS. The role of high dietary protein in the management of the MetS is still controversial, thus preventing the development of clear guidelines on high-protein diets and the type of proteins to be recommended. ${ }^{30}$ Similarly, the benefits of high fruit and dairy intake on MetS is still debatable, ${ }^{31,32}$ while regular exercise has been associated with reduction in the risk of MetS. ${ }^{33}$

\section{Conclusions}

We report that the MetS is modestly prevalent in adolescents in Mthatha. As childhood overweight/obesity often continues into adulthood, it is important to address the causes of increased risk for the MetS earlier in life to prevent disease development in adult life. We recommend that further research be carried out in this population with a larger sample size with equal numbers of females and males in order to clarify the risk of MetS in South African adolescents of African ancestry.

\section{Acknowledgments}

Prof BN Nkeh-Chungag is the guarantor of this work and, as such, had full access to all the data in the study and takes responsibility for the integrity of the data and the accuracy of the data analysis. We also wish to thank the participants and their families for their time and patience.

This project was supported by the South African Medical Research Council and the Walter Sisulu University. The funders had no role in the data collection, data analysis or interpretation or in the preparation of the manuscript.

\section{Authors' contributions}

MAS helped in data collection and project write-up. NG analyzed the data and prepared and edited the manuscript. CRSR contributed in data collection, data analysis and manuscript preparation. JEI helped in project conception, data analysis and manuscript preparation. BNNC contributed in project conception, data collection, data analysis and manuscript preparation. All authors contributed toward data analysis, drafting and critically revising the paper and agree to be accountable for all aspects of the work.

\section{Disclosure}

The authors report no conflicts of interest in this work.

\section{References}

1. Mottillo S, Filion KB, Genest J, et al. The metabolic syndrome and cardiovascular risk a systematic review and meta-analysis. $\mathrm{J} \mathrm{Am} \mathrm{Coll}$ Cardiol. 2010;56(14):1113-1132.

2. Esser N, Legrand-Poels S, Piette J, Scheen AJ, Paquot N. Inflammation as a link between obesity, metabolic syndrome and type 2 diabetes. Diabetes Res Clin Pract. 2014;105(2):141-150.

3. Gurka MJ, Lilly CL, Oliver MN, DeBoer MD. An examination of sex and racial/ethnic differences in the metabolic syndrome among adults: a confirmatory factor analysis and a resulting continuous severity score. Metabolism. 2014;63(2):218-225.

4. Bonomini F, Rodella LF, Rezzani R. Metabolic syndrome, aging and involvement of oxidative stress. Aging Dis. 2015;6(2):109-120.

5. Fauci AS. Harrison's Principle of Internal Medicine. New York, NY: McGraw-Hill Medical; 2008.

6. De Ferranti SD, Gauvreau K, Ludwig DS, Neufeld EJ, Newburger JW, Rifai N. Prevalence of the metabolic syndrome in American adolescents. Findings from the third national health and nutrition examination survey. Circulation. 2004;110(16):2494-2497.

7. Martino F, Puddu PE, Pannarale G, et al. Metabolic syndrome among children and adolescents from Southern Italy: contribution from the Calabrian Sierras Community (CSCS). Int J Cardiol. 2014;177(2): 455-460.

8. The IDF Consensus Worldwide Definition of the Metabolic Syndrome. Brussels 2006: International Diabetes Federation. Available from: https://www.idf.org/webdata/docs/MetS_def_update2006.pdf. Accessed July 18, 2016.

9. Zimmet P, Alberti G, Kaufman F, et al; IDF Consensus Group. The metabolic syndrome in children and adolescents: the IDF consensus. Pediatr Diabetes. 2007;8(5):299-306.

10. World Health Organization. Definition, diagnosis and classification of diabetes mellitus and its complications: report of WHO a Consultation 1999. Part 1: diagnosis and classification of diabetes mellitus. Geneva.

11. Cook S, Weitzman M, Auinger P, Nguyen M, Dietz WH. Prevalence of metabolic syndrome phenotype in adolescents: findings from the third National Health and Nutrition Examination Survey, 1988-1994. Arch Pediatr Adolesc Med. 2003;157(8):825-827.

12. IDPAIA. I guideline for preventing atherosclerosis in childhood and adolescence. Int $J$ Atheroscler. 2006;1:1-30.

13. Neto AS, de Campos W, dos Santos GC, Mazzardo JO. Metabolic syndrome risk score and time expended in moderate to vigorous physical activity in adolescents. BMC Pediatr. 2014;14:42.

14. Rosini N, Oppermann Moura SAZ, Rosini RD, Machado MJ, de Silva EL. Metabolic Syndrome and importance of associated variables in children and adolescents in Guabiruba - SC, Brazil. Arq Bras Cardiol. 2015; 105(1):37-44.

15. Pienaar AE. Prevalence of overweight and obesity among primary school children in a developing country: NW-CHILD longitudinal data of 6-9-yr-old children in South Africa. BMC Obesity. 2014;2:2.

16. Monyeki MA, Awotidebe A, Strydom GL, de RidderJ H, Mamabolo RL, Kemper HCG. The challenges of underweight and overweight in South African children: are we winning or losing the battle? A systematic review. Int J Environ Res Public Health. 2015;12(2):1156-1173.

17. Nkeh-Chungag BN, Sekokotla AM, Sewani-Rusike C, Namugowa A, Iputo JE. Prevalence of hypertension and pre-hypertension in 13-17 year old adolescents living in Mthatha-South Africa: a cross sectional study. Cent Eur J Public Health. 2015;23(1):211-214.

18. American Diabetic Association (ADA). Type 2 diabetes in children and adolescents. Diabetes Care. 2000;23(3):381-389.

19. Kimani-Murage EW, Kahn K, Pettifor JM, et al. The prevalence of stunting, overweight and obesity, and metabolic disease risk in rural South African children. BMC Public Health. 2010;10:158-117.

20. Griffith PL, Sheppard Z, Johnson W, Cameron N, Pettifor J, Norris SA. Associations between household and neighbourhood socio-economic status and systolic blood pressure among urban South African adolescents. J Biosocial Sci. 2012;44(4):433-458. 
21. Serrano MDM, Armesilla MDC, Moreno MMC, et al. Association between adiposity and blood pressure levels between the ages of 6 and 16 years analysis in a student population from Madrid, Spain. Rev Esp Cadiol. 2013;66(2):110-115.

22. Falkner B. Hypertension in children and adolescents: epidemiology and natural history. Pediatr Nephrol. 2010;25(7):1219-1224.

23. Head GA. Cardiovascular and metabolic consequences of obesity. Front Physiol. 2015;6:1-3.

24. Bitzur R, Cohen H, Kamari Y, Shaish A, Harats D. Triglycerides and HDL cholesterol. Star or second leads in diabetes. Diabetes Care. 2009; 32(Suppl 2):S373-S377.

25. Martin SS, Michos ED. Mapping hyperlipidemia in young adulthood to coronary risk: importance of cumulative exposure and how to stay young. Circulation. 2015;131(5):445-447.

26. Wong BW, Meredith A, Lin D, McManus BM. The biological role of inflammation in atherosclerosis. Canad J Cardiol. 2012; 28(6):631-641.

27. Villa JKD, e Silva AR, Santos TSS, Ribeiro AQ, da Rocha Sant'Ana LF. Metabolic syndrome risk assessment in children: use of a single score. Rev Paul Pediatr. 2015;33(2):187-193.
28. Ahrens W, Moreno LA, Marild S, et al. Metabolic syndrome in young children: definitions and results of the IDEFICS study. Int J Obesity. 2014;38(Suppl 2):S4-S14.

29. WHO Expert Consultation, (2011). Waist Circumference and Waist-Hip Ratio: Report of a WHO Expert Consultation. Geneva: 8-11;2008. Available from: http://whqlibdoc.who.int/publications/2011/9789241501491_eng. pdf. Accessed August 25, 2012.

30. Wojcik J, Aukema HM, Zahradka P, Taylor CG. Effects of high protein diets on metabolic syndrome parameters. Curr Opin Food Sci. 2016;8:43-49.

31. Shin BR, Choi YK, Kim HN, Song SW. High dietary calcium intake and a lack of dairy consumption are associated with metabolic syndrome in obese males: the Korean National Health and Nutrition Examination Survey 2010 to 2012. Nutr Res. 2016;36(6):518-525.

32. Shin YJ, Kim JY, Kang HT, Han KH, Shin JY. Effect of fruits and vegetables on metabolic syndrome: a systematic review and metaanalysis of randomized controlled trials. Int J Food Sci Nutr. 2015;66(4) 415-425.

33. McMurray RG. The influence of exercise on metabolic syndrome in youth: a review. Am J Lifestyle Med. 2010;4(2):176-186.
Therapeutics and Clinical Risk Management

\section{Publish your work in this journal}

Therapeutics and Clinical Risk Management is an international, peerreviewed journal of clinical therapeutics and risk management, focusing on concise rapid reporting of clinical studies in all therapeutic areas, outcomes, safety, and programs for the effective, safe, and sustained use of medicines. This journal is indexed on PubMed Central, CAS,

\section{Dovepress}

EMBase, Scopus and the Elsevier Bibliographic databases. The manuscript management system is completely online and includes a very quick and fair peer-review system, which is all easy to use. Visit http://www.dovepress.com/testimonials.php to read real quotes from published authors.

Submit your manuscript here: http://www.dovepress.com/therapeutics-and-clinical-risk-management-journal 